\title{
Should We Stop Calling Thanatophoric Dysplasia a Lethal Condition? A Case Report of a Long-Term Survivor
}

\author{
Ricki S. Carroll, MD, MBE, ${ }^{1-3, *}$ Angela L. Duker, MS, CGC, ${ }^{1}$ Andrea J. Schelhaas, MS, CGC, \\ Mary Ellen Little, BSN, RNC-NIC, ${ }^{1}$ Elissa G. Miller, MD, ${ }^{2,3}$ and Michael B. Bober, MD, PhD ${ }^{1,3}$
}

\begin{abstract}
Thanatophoric dysplasia (TD) is a rare skeletal dysplasia commonly thought to be lethal. In this case report, we discuss a nine-year-old male with TD and review his parents' decision making shortly after their son was born, the technology needed to sustain him, and his parents' perception of his quality of life. We also summarize the clinical course of published long-term survivors with TD. Pediatric Palliative Care teams, especially those conducting perinatal palliative care consultations, are often asked to support families in the face of prognostic uncertainty. Our case report and review of the literature adds to the uncertainty of prognosis in TD and suggests that pediatric palliative care providers should be wary of the label "lethal."
\end{abstract}

Keywords: lethal condition; pediatric palliative care; perinatal palliative care; prognosis; rare disease; skeletal dysplasia; thanatophoric dysplasia

\section{Introduction}

Thanatophoric dysplasia (TD) is a skeletal dysplasia that was previously described to be incompatible with life. The term thanatophoric is Greek for "death bearing." Infants with this condition have extreme short stature, micromelia, a narrow chest, underdeveloped lungs, macrocephaly, and a small foramen magnum. Occurring in $1 / 20,000$ to $1 / 50,000$ births, it was understood to be lethal soon after birth due to difficulty with ventilation and development of respiratory failure. ${ }^{1-4}$ There are very few reports of patients who have survived beyond the first few days of life; therefore, families faced with this diagnosis are typically counseled to consider pregnancy termination and/or comfort care at birth. However, with advances in technology, survival can be possible for some. This makes counseling around prognosis and expected clinical course chal- lenging for families faced with a perinatal diagnosis of TD.

In this brief report, we describe the case of a boy with thanatophoric dysplasia type 1 (TD1) and review the medical decisions the family faced. We also summarize the clinical course of published long-term survivors with TD. Both serve not only as prognostic guides for this specific condition but also to illustrate themes that emerge when providing palliative care for children with diseases commonly labeled as "lethal." The family gave permission for their child's name and story to be shared.

\section{Case Description}

Charlie was born to a 33-year-old gravida 7 para 3 mother and a 33-year-old father. Pregnancy was complicated by polyhydramnios and features suggestive of TD by anatomical ultrasound. Amniocentesis

\footnotetext{
Divisions of ${ }^{1}$ Orthogenetics and ${ }^{2}$ Palliative Medicine, Nemours/Alfred I. duPont Hospital for Children, Wilmington, Delaware, USA.

${ }^{3}$ Sidney Kimmel Medical College, Thomas Jefferson University, Philadelphia, Pennsylvania, USA.

*Address correspondence to: Ricki S. Carroll, MD, MBE, Division of Orthogenetics, Nemours/Alfred I. duPont Hospital for Children, 1600 Rockland Road, Wilmington, DE 19803, USA, E-mail: ricki.carroll@nemours.org
}

() Ricki S. Carroll et al., 2020; Published by Mary Ann Liebert, Inc. This Open Access article is distributed under the terms of the Creative Commons License (http://creativecommons.org/licenses/by/4.0), which permits unrestricted use, distribution, and reproduction in any medium, provided the original work is properly cited. 
identified a c.742C $>\mathrm{T}$ (p.R248C) mutation in FGFR3, consistent with a diagnosis of TD1. Charlie's mother recalls being given the diagnosis by a high-risk obstetrician and a genetic counselor who both counseled that, if she were to carry to term, the infant would not make it out of the delivery room alive and, therefore, offered termination of the pregnancy. After connecting with two families whose children were long-term survivors with TD, they made the decision to continue the pregnancy. Charlie's mother met with her local neonatology team and together they created a birth plan that supported her goal of prolonging Charlie's life.

Delivery occurred at 36 weeks gestation through repeat cesarean section, and the infant required intubation and ventilator support immediately after birth. He spent five months in the neonatal intensive care unit where he received frequent speech, physical, and occupational therapy. Tracheostomy and gastric tube were placed at two weeks of age. He was treated for subclinical seizures and had challenges with hypoventilation and apnea, all of which improved with time. $\mathrm{He}$ was discharged to a rehabilitation facility for one month before going home.

He presented to our skeletal dysplasia program for multidisciplinary evaluation at 2.5 years of age. At that time, he had been generally healthy with one hospital admission for treatment of pneumonia since birth. He was able to roll from his back to his stomach and also used a power wheelchair for mobility. He was able to feed primarily by mouth with assistance, utilizing the gastric tube infrequently. Polysomnography obtained around this time demonstrated periodic breathing and central apnea with oxygen desaturations, and his neurological examination was notable for hypotonia, weakness, hyperreflexia, and crossed adductor reflexes, raising the concern for critical foramen magnum stenosis. Magnetic resonance imaging of the cervical spine and craniocervical junction identified a narrowed foramen magnum and diffuse narrowing of the cervical canal with signal changes within the spinal cord, and he subsequently underwent foramen magnum decompression the following month. After surgery, his developmental skills advanced significantly and his central apneas resolved.

At four years, his gastric tube had been removed and his ventilator settings were being slowly weaned over time. Acanthosis nigricans, a known skin finding in children with changes in the FGFR3 gene unrelated to glucose intolerance, was first observed in Charlie at approximately two years of age and had begun to spread within skin folds and areas of friction. $\mathrm{He}$ would go on to have surgical excision of these skin folds multiple times in an effort to reduce the complications that arose in these areas.

Repeat evaluation each year since has demonstrated consistent progression of developmental skills. At seven years of age, he was able to army crawl, bear weight in a jumper, and sit unsupported for one hour. With the assistance of a communication device, as well as sign language, he was able to use up to threeword phrases to communicate his needs and answer questions, including asking for specific foods and activities. Neuropsychiatric testing placed him at the one- to three-year-old level, with the caveat that standardized testing is made for children who experience the world much different than Charlie; therefore, it was noted to better describe him functioning within the sensorimotor developmental stage. Today, Charlie's mother described him as "a thriving 9-year-old boy" (Fig. 1) who feeds himself, drives his own power chair, throws a ball, colors, and paints. He has been weaned off the ventilator since eight years of age, and is now working toward decannulation, of which we believe he would be the first child with TD1 to accomplish.

\section{Discussion}

Expected clinical course

A crucial role that palliative care providers serve is to help families gain a better understanding of their child's prognosis and expected clinical course. This can be challenging when a fetus or a child carries a rare diagnosis and/or has surpassed prognostic expectations. A summary of the medical needs of published longterm survivors with TD can be found in Table $1 .^{5-14}$ Although the number of published individuals living with TD1 are few, knowing the medical decisions and interventions these children required can be helpful when families turn to us for guidance. ${ }^{15}$

Respiratory. Infants with TD face challenges with ventilation. We hypothesize that this is due to a combination of upper airway obstruction, tracheomalacia, abnormal pulmonary anatomy, and pulmonary hypoplasia due to small ribs and a narrow chest. ${ }^{16}$ Although we suspect that infants with TD who are unable to be ventilated despite all interventions are in the majority, we note that there is a subset of patients who have the potential to survive when offered respiratory support.

As in Charlie's case, all published individuals with TD who have survived beyond one year of life have 


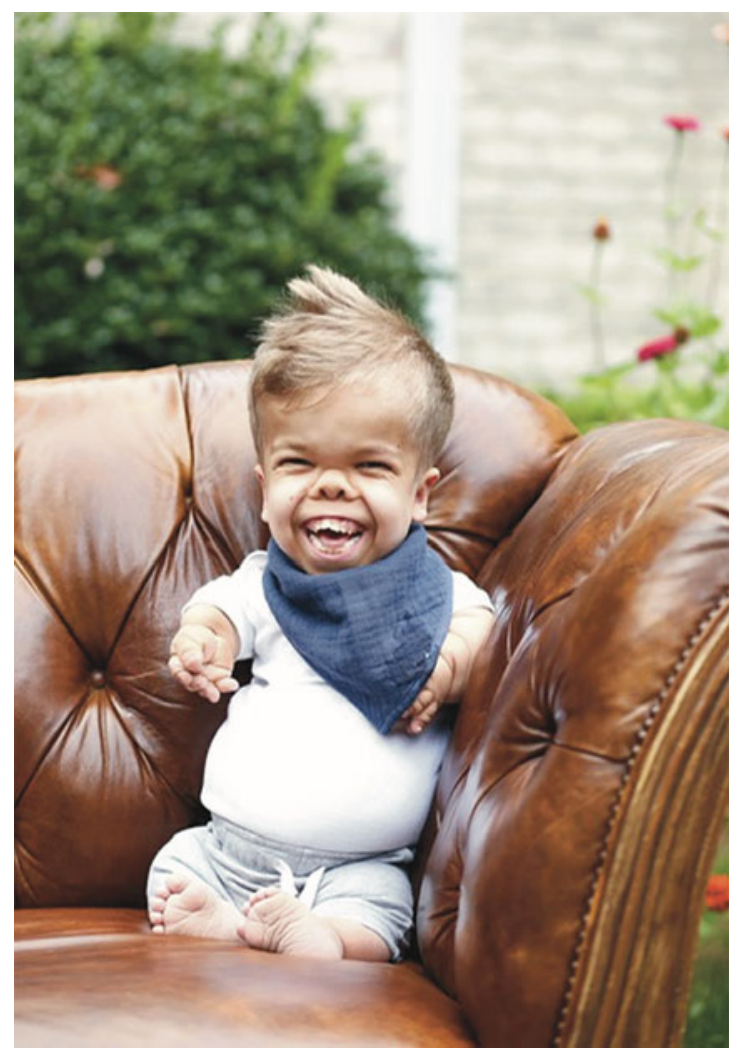

FIG. 1. Charlie at nine years of age in the front yard of his home.

required long-term mechanical ventilation (Table 1). Most patients required tracheostomy, although one described patient utilized long-term endotracheal intubation. ${ }^{6,7}$ Several individuals were able to experience brief ventilator-free windows throughout the day; however, there are no published reports before this one of individuals completely weaned off of invasive respiratory support. It is worth noting that one child has been reported to have tolerated periods of time off ventilation, but later developed neurological sequelae, leading to complete ventilator dependence by the end of her second decade. ${ }^{9}$

Neurological. As seen in achondroplasia, the anteriorposterior diameter of the foramen magnum can be significantly narrowed in TD. This may present with neurological changes, developmental delays, and/or central apnea. Foramen magnum decompression can provide relief of pressure on the spine for those with critical stenosis. We anecdotally witnessed significant improve- ments in all three of these domains for our patient after decompression surgery. However, as noted earlier, an individual has been described for whom there was progression of cervical spinal stenosis in the second decade of life despite decompression as a child, leading to quadriplegia as a teenager and regression to need of complete ventilator support. ${ }^{9}$

On brain imaging, a majority of children in the literature had ventriculomegaly and/or temporal lobe dysplasia or dysgenesis; however, only two children had a ventriculoperitoneal shunt placed (Table 1). ${ }^{4,8,9,17-22}$ Seizures were common, typically temporal lobe epilepsy, but seemed to be manageable with antiepileptic medications. ${ }^{5,9}$

Developmental delays are expected. The individual described in this study demonstrated slow and steady developmental progress over time, with intensive therapies and augmentative communication devices. Early intervention should be involved; however, physical therapy should avoid any manipulations of the neck or back so as to not exacerbate injury due to the condition-associated foramen magnum stenosis and thoracolumbar kyphosis. Expectations should not be that a child with TD will be conversant and ambulatory without assistive devices, but that there is potential for developmental advancement. ${ }^{9}$

Dermatological. Acanthosis nigricans is a consistent feature that appears to develop in individuals with TD. This is not a surprising finding as acanthosis nigricans is observed in several other FGFR3-related disorders. ${ }^{23-25}$ Using a lubricant in locations of friction can sometimes slow the progression and prevent skin breakdown. Alternatively, surgical excision can be beneficial for some children with widespread acanthosis if it is causing significant discomfort or risk of infection.

Growth. Growth velocity for children with TD is not known; however, the child in our case showed steady length, chest, and head circumference growth over time. We suggest growth points for a child with TD be best plotted on achondroplasia growth charts, with expectations that the head circumference would plot above the mean, and the height would plot more than two standard deviations below the mean. To this end, infants with TD inevitably have different weight goals, and we suggest a goal of 5 to $10 \mathrm{~g} /$ day in the first year of life. Weight gain above this amount can cause reflux, vomiting, and abdominal competition leading to increased respiratory needs. 


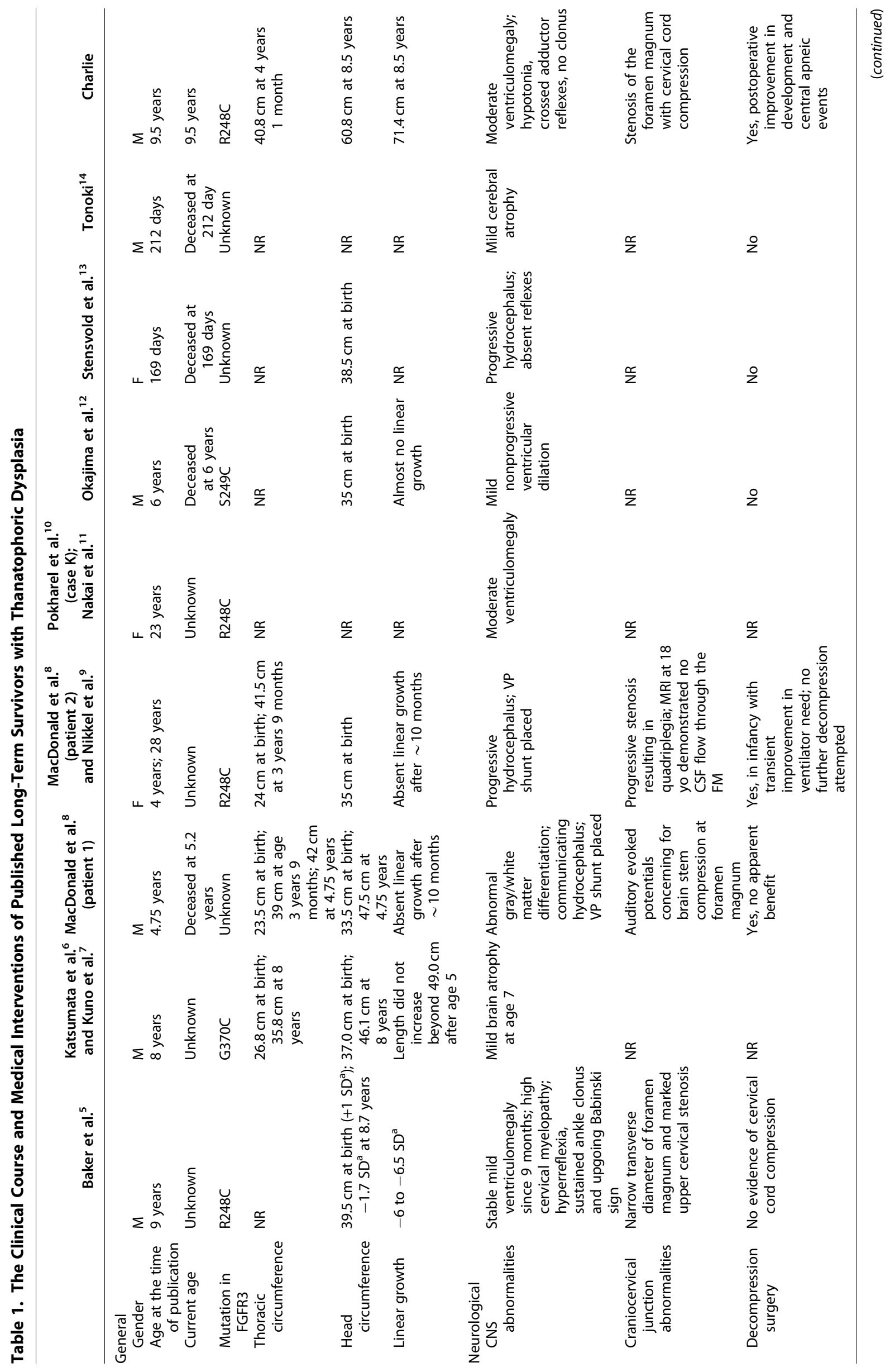




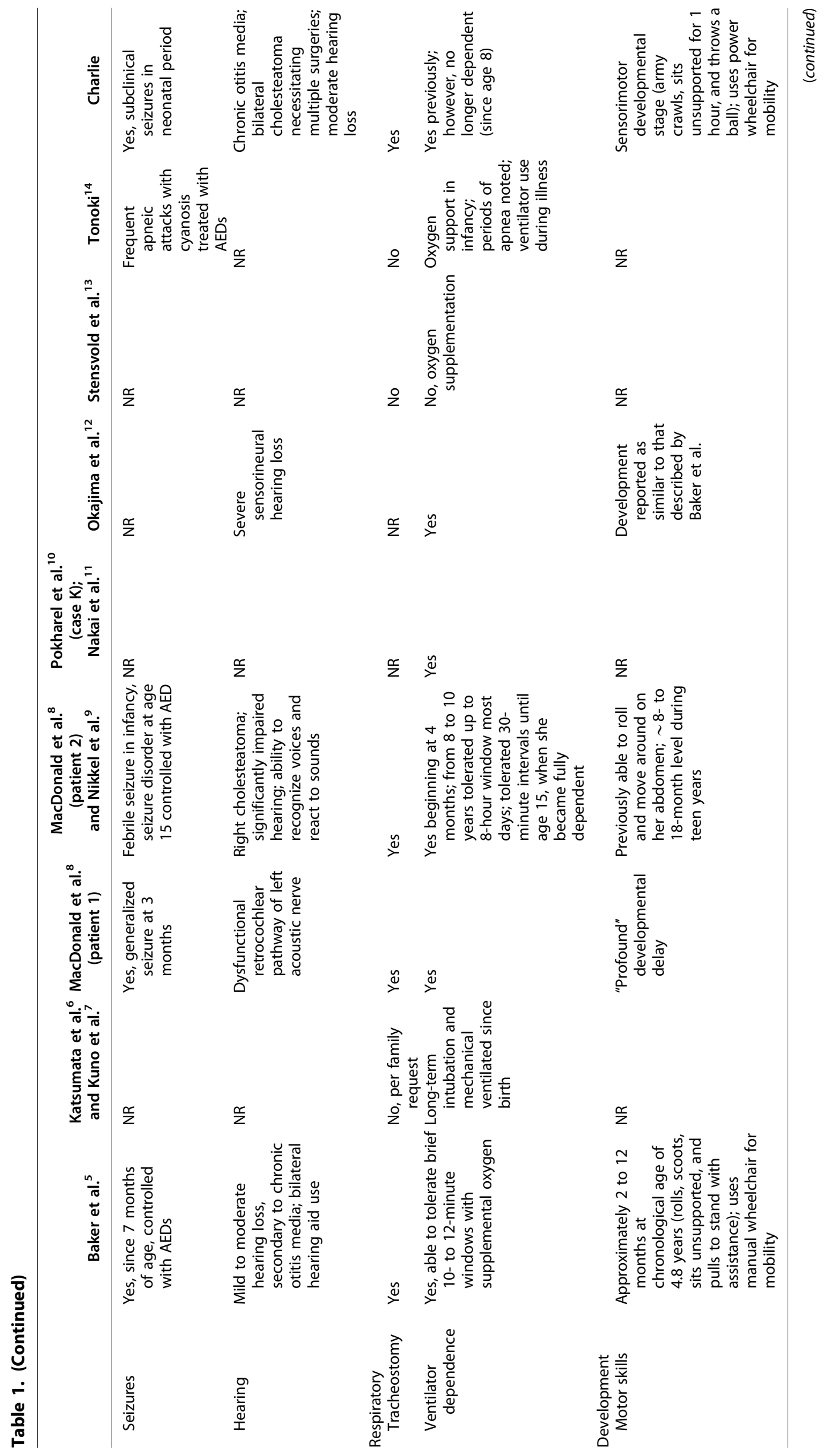




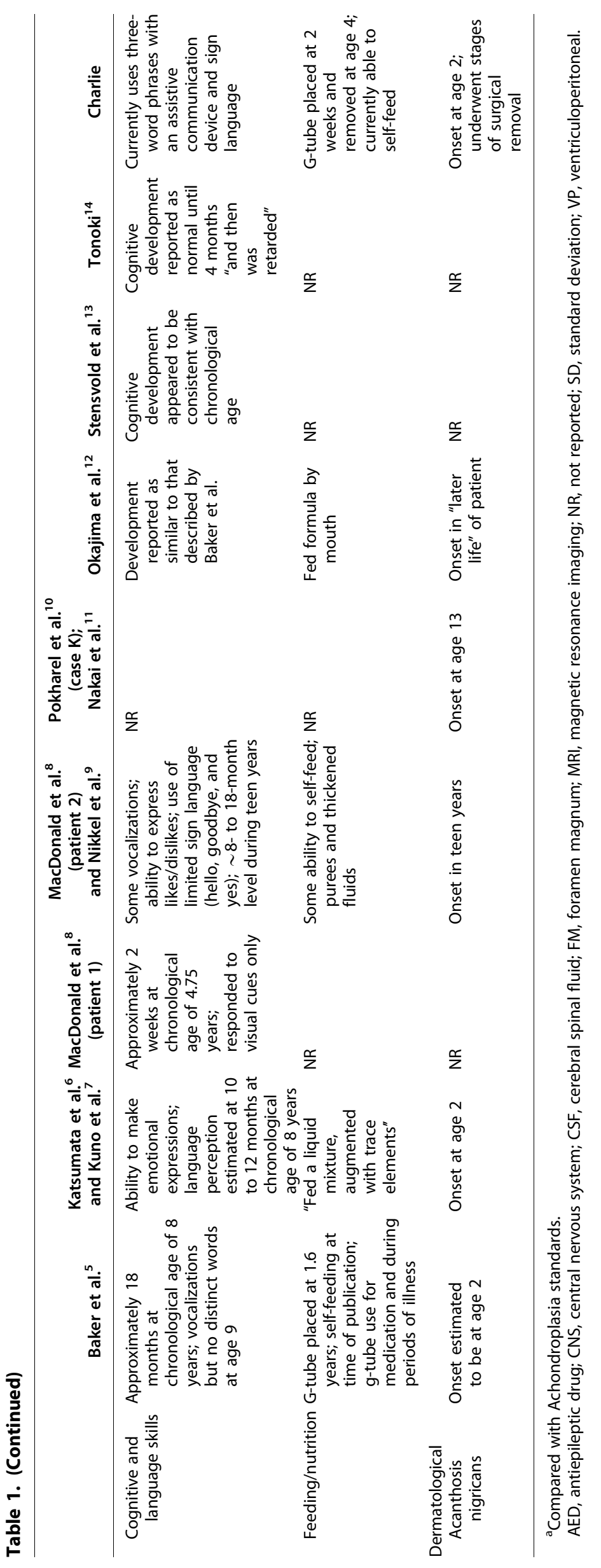


Potential for future treatment

C-type natriuretic peptide (CNP) is a potent positive regulator of endochondral bone growth. Studies have shown that CNP plasma levels are altered in FGFR3opathies. ${ }^{26}$ Currently, clinical trials are underway testing the use of CNP analogues in children with achondroplasia. These studies are in progress, but early results show a modest increase in height. ${ }^{27}$ Although linear growth is one outcome being measured, the hope is that this treatment will decrease medical complications caused by skeletal changes in achondroplasia. There are also several other potential therapeutic agents for achondroplasia that are early in their development. We would be remiss if we did not mention the possibility of these medications being helpful to children with TD in the future as well. This is important to note as it further evidences the evolving clinical landscape for children with TD and informs the way in which palliative care physicians will need to counsel families about future potential and prognosis.

The role of the palliative care team

in an evolving landscape

The story of children such as Charlie surviving with a "lethal" disease is not unfamiliar in pediatric palliative care (PPC). Trisomy 13 and 18 (T13/18), once considered mostly fatal, are now well established as syndromes with wide phenotypic variation, and children are known to survive for decades both with and without surgical intervention. ${ }^{28-30} \mathrm{TD}$ in some ways is today where T13/18 were in the 1980s-with single case reports of long-term survivors, such as Charlie, and parents fighting for medical providers to consider alternatives. ${ }^{31}$

Although we currently lack longitudinal data in TD, we can extrapolate that with surgical intervention (tracheostomy, gastric tube placement, foramen magnum decompression, and/or ventriculoperitoneal (VP) shunt when clinically indicated), survival curves are likely to differ from what we would expect with a "uniformly fatal" diagnosis. Quality of life (QOL), of course, is important to follow, along with survival. If Charlie is any indication, his parents perceive his QOL to be excellent and state they would do nothing differently if they were faced with the same medical decisions for Charlie all over again.

As with the paradigm shift that has occurred in the care of infants with T13/18, PPC teams have played and continue to play a pivotal role in advocating for goal-concordant clinical care that is based on best avail- able evidence for the disease in question. With rare diseases such as TD, single case reports of survivors such as Charlie are important evidence that a condition may be life-limiting, but not necessarily "uniformly lethal." We, therefore, recommend practitioners be wary of the label "lethal" and suggest counseling families on the variety of clinical outcomes documented in the literature.

\section{Acknowledgements}

We thank Charlie and his family for allowing us to share his story.

\section{Funding Information}

No funding was received.

\section{Author Disclosure Statement}

Drs. Bober and Carroll are investigators for Biomarin, Pfizer, QED, and Ascendis. Dr. Bober also serves as a consultant for these companies. No competing financial interests exist for the rest of the authors on this article.

\section{References}

1. Wilcox WR, Tavormina PL, Krakow D, et al.: Molecular, radiologic, and histopathologic correlations in thanatophoric dysplasia. Am J Med Genet 1998;78:274-281.

2. Baitner AC, Maurer SG, Gruen MG, Di Cesare PE: The genetic basis of the osteochondrodysplasias. J Pediatr Orthop 2000;20:594-605.

3. Chen CP, Chern SR, Shih JC, et al.: Prenatal diagnosis and genetic analysis of type I and type II thanatophoric dysplasia. Prenat Diagn 2001;21:89-95.

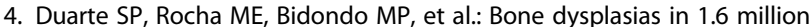
births in Argentina. Eur J Med Genet 2019;62:103603.

5. Baker KM, Olson DS, Harding CO, Pauli RM. Long-term survival in typical thanatophoric dysplasia type 1. Am J Med Genet 1997;70:427-436.

6. Katsumata N, Kuno T, Miyazaki S, et al.: G370C mutation in the FGFR3 gene in a Japanese patient with thanatophoric dysplasia. Endocr J 1998; 45(Suppl):S171-S174.

7. Kuno T, Fujita I, Miyazaki S, Katsumata N: Markers for bone metabolism in a long-lived case of thanatophoric dysplasia. Endocr J 2000;47(Suppl): S141-S144.

8. MacDonald IM, Hunter AG, MacLeod PM, MacMurray SB: Growth and development in thanatophoric dysplasia. Am J Med Genet 1989;33:508-512.

9. Nikkel SM, Major N, King WJ: Growth and development in thanatophoric dysplasia-An update 25 years later. Clin Case Rep 2013;1:75-78.

10. Pokharel RK, Alimsardjono H, Takeshima $\mathrm{Y}$, et al.: Japanese cases of type 1 thanatophoric dysplasia exclusively carry a $C$ to $T$ transition at nucleotide 742 of the fibroblast growth factor receptor 3 gene. Biochem Biophys Res Commun 1996;227:236-239.

11. Nakai K, Yoneda K, Moriue T, et al.: Seborrhoeic keratosis and acanthosis nigricans in a long-term survivor of thanatophoric dysplasia. Br J Dermatol 2010;163:656-658.

12. Okajima K, Asai K, Niwa T, et al.: Clinical and biochemical findings of a patient with thanatophoric dysplasia type I: Additional finding of dicarboxylic aciduria. Cleft Palate Craniofac J 2002;39:246-248.

13. Stensvold K, Ek J, Hovland AR: An infant with thanatophoric dwarfism surviving 169 days. Clin Genet 1986;29:157-159.

14. Tonoki H: A boy with thanatophoric dysplasia surviving 212 days. Clin Genet 1987;32:415-416.

15. Sawai H, Oka K, Ushioda M, et al.: National survey of prevalence and prognosis of thanatophoric dysplasia in Japan. Pediatr Int 2019;61:748-753.

16. Bober MB, Taylor M, Heinle R, Mackenzie W: Achondroplasiahypochondroplasia complex and abnormal pulmonary anatomy. Am J Med Genet Part A 2012;158A:2336-2341. 
17. Wang DC, Shannon P, Toi A, et al.: Temporal lobe dysplasia: A characteristic sonographic finding in thanatophoric dysplasia. Ultrasound Obstet Gynecol 2014;44:588-594.

18. Blaas HG, Vogt C, Eik-Nes SH: Abnormal gyration of the temporal lobe and megalencephaly are typical features of thanatophoric dysplasia and can be visualized prenatally by ultrasound. Ultrasound Obstet Gynecol 2012; 40:230-234.

19. Miller E, Blaser S, Shannon P, Widjaja E: Brain and bone abnormalities of thanatophoric dwarfism. AJR Am J Roentgenol 2009;192:48-51.

20. Knisely AS, Ambler MW: Temporal-lobe abnormalities in thanatophoric dysplasia. Pediatr Neurosci 1988;14:169-176.

21. Tan AP, Priego G: Thanatophoric dysplasia type 1 with tectal plate dysplasia and aqueductal stenosis. Childs Nerv Syst 2019;35:1059-1061.

22. Soo-Kyeong J, Lee N, Bae MH, et al.: Chylous ascites in an infant with thanatophoric dysplasia type I with FGFR3 mutation surviving five months. Fetal Pediatr Pathol 2018;37:363-371.

23. Bellus GA, Bamshad MJ, Przylepa KA, et al.: Severe achondroplasia with developmental delay and acanthosis nigricans (SADDAN): Phenotypic analysis of a new skeletal dysplasia caused by a Lys650Met mutation in fibroblast growth factor receptor 3. Am J Med Genet 1999; 85:53-65.

24. Blomberg M, Jeppesen E, Skovby F, Benfeldt E: FGFR3 mutations and the skin: Report of a patient with a FGFR3 gene mutation, acanthosis nigricans, hypochondroplasia and hyperinsulinemia and review of the literature. Dermatology 2010;220:297-305.

25. Meyers GA, Orlow SJ, Munro IR, et al.: Fibroblast growth factor receptor 3 (FGFR3) transmembrane mutation in Crouzon syndrome with acanthosis nigricans. Nat Genet 1995;11:462-464.

26. Olney RC, Prickett TCR, Espiner EA, et al.: C-type natriuretic peptide plasma levels are elevated in subjects with achondroplasia, hypochondroplasia, and thanatophoric dysplasia. J Clin Endocrinol Metab 2015;100: E355-E359.

27. Savarirayan $R$, Irving $M$, Bacino CA, et al.: C-type natriuretic peptide analogue therapy in children with achondroplasia. N Engl J Med 2019;381: 25-35.
28. Nelson KE, Hexem KR, Feudtner C: Inpatient hospital care of children with trisomy 13 and trisomy 18 in the United States. Pediatrics 2012;129:869876.

29. Nelson KE, Rosella LC, Mahant S, Guttmann A: Survival and surgical interventions for children with trisomy 13 and 18. JAMA 2016;316:420-428.

30. Kosiv KA, Gossett JM, Bai S, Collins RT 2nd: Congenital heart surgery on inhospital mortality in trisomy 13 and 18. Pediatrics 2017;140:e20170772.

31. Nguyen JE, Salemi JL, Tanner JP, et al.: Survival and healthcare utilization of infants diagnosed with lethal congenital malformations. J Perinatol 2018;38:1674-1684.

Cite this article as: Carroll RS, Duker AL, Schelhaas AJ, Little ME, Mille EG, Bober MB (2020) Should we stop calling thanatophoric dysplasia a lethal condition? A case report of a long-term survivor, Palliative Medicine Reports 1:1, 32-39, DOI: 10.1089/pmr.2020.0016.

$\begin{aligned} & \text { Abbreviations Used } \\ & \mathrm{AED}=\text { antiepileptic drug } \\ & \mathrm{CNS}=\text { central nervous system } \\ & \mathrm{CSF}=\text { cerebral spinal fluid } \\ & \mathrm{CNP}=\text { C-type natriuretic peptide } \\ & \mathrm{FM}=\text { foramen magnum } \\ & \mathrm{MRI}=\text { magnetic resonance imaging } \\ & \mathrm{NR}=\text { not reported } \\ & \mathrm{PPC}=\text { pediatric palliative care } \\ & \mathrm{QOL}=\text { quality of life } \\ & \mathrm{SD}=\text { standard deviation } \\ & \mathrm{TD}=\text { thanatophoric dysplasia } \\ & \mathrm{TD} 1=\text { thanatophoric dysplasia type } 1 \\ & \mathrm{~T} 13 / 18=\text { trisomy } 13 \text { and } 18 \\ & \mathrm{VP}=\text { ventriculoperitoneal }\end{aligned}$

\section{Publish in Palliative Medicine Reports}

\begin{tabular}{|l|l|l}
\hline $\begin{array}{l}\text { Palliative } \\
\text { Medicine } \\
\text { Reports }\end{array}$ & - Immediate, unrestricted online access \\
& - Rigorous peer review \\
& - Compliance with open access mandates \\
& - Authors retain copyright \\
- Highly indexed \\
- Targeted email marketing
\end{tabular}

